\title{
Suicide attempt by self-stabbing of the bladder: a case report
}

\author{
Youssef Kharbach ${ }^{1 *}$, Somuah Tenkorang ${ }^{1}$, Mustapha Ahsaini ${ }^{1}$, Soufiane Mellas ${ }^{1,2}$, Jalaleddine El Ammari ${ }^{1}$, \\ Mohammed Fadl Tazi ${ }^{1}$, Abdelhak Khallouk', Mohammed Jamal El Fassi ${ }^{1}$ and Moulay Hassan Farih ${ }^{1}$
}

\begin{abstract}
Introduction: The presence of foreign bodies in the bladder often falls within questionable practices in psychiatric settings or in iatrogenic instances such as during endoscopy or migration of foreign bodies around the bladder remaining after surgery on organs close to the bladder. Psychiatric disorders have been reported in patients admitted for self-introduction of foreign bodies in the bladder during an act of sexual satisfaction. However, to the best of our knowledge, no similar case in the context of suicide has been reported in the English-language literature.

Case presentation: A 56-year-old Moroccan man known to have untreated paranoid schizophrenia and a history of several previous suicide attempts was presented to the emergency unit of our hospital after self-stabbing with a $15 \mathrm{~cm}$ sewing needle. His stab wound was located at the hypogastric region of the abdomen, with full penetration of the needle into the abdomen. A computed tomographic scan showed a breach on the dome of the bladder responsible for extravasation of the contrast dye, which revealed a peritoneal cavity effusion of average abundance and a suspected lesion of the left pelvic ureter. An exploratory laparotomy was performed. Approximately $1000 \mathrm{~mL}$ of widely dispersed fluid was observed in the abdominal cavity. During exploration of the bladder, two centimetric intrabladder breaches were found, one of which was a breach of the left pelvic ureter without other associated lesions. The breaches were sutured, and a ureteral catheter was mounted. The patient's post-operative follow-up was unremarkable.
\end{abstract}

Conclusions: The wide variety of ways that foreign bodies are introduced into the lower urinary tract pose diagnostic and therapeutic difficulties for the urologist. Management of these patients is facilitated by the use of endoscopy.

Keywords: Foreign body, Urinary bladder

\section{Introduction}

The discovery of foreign bodies in the bladder always raises questions about the circumstances of introduction or migration of these materials, as well as the psychological profile of the patient. This condition can be lifethreatening. Timely and appropriate medical care should be accompanied by psychiatric care in such cases.

\section{Case presentation}

A 56-year-old Moroccan man known to have untreated paranoid schizophrenia with a history of several suicide attempts was presented to the emergency room of our institution six hours after self-stabbing with a $15 \mathrm{~cm}$ sewing needle that had entirely penetrated into his

\footnotetext{
* Correspondence: dr.kharbach@gmail.com

'Department of Urology, Hassan II University Hospital, Fez, Morocco

Full list of author information is available at the end of the article
}

abdomen. Upon clinical examination, he was found to be conscious with incoherent speech and stable vital signs. During his abdominal examination, three entry points were found at the hypogastric region (one on the midline and two on the right side) with generalized abdominal tenderness. The patient presented neither hematuria nor rectal bleeding.

An X-ray of the abdomen revealed a sewing needle projecting into the bladder area with no signs of pneumoperitoneum (Figure 1).

A computed tomographic (CT) scan and a cystogram both showed a breach on the dome of the bladder visualized as extravasation of contrast dye, peritoneal effusion of average abundance and a suspected lesion of the left pelvic ureter, with no lesions in the digestive tract (Figures 2 and 3).

The patient was admitted to the operating room, where an exploratory laparotomy was performed. Approximately 


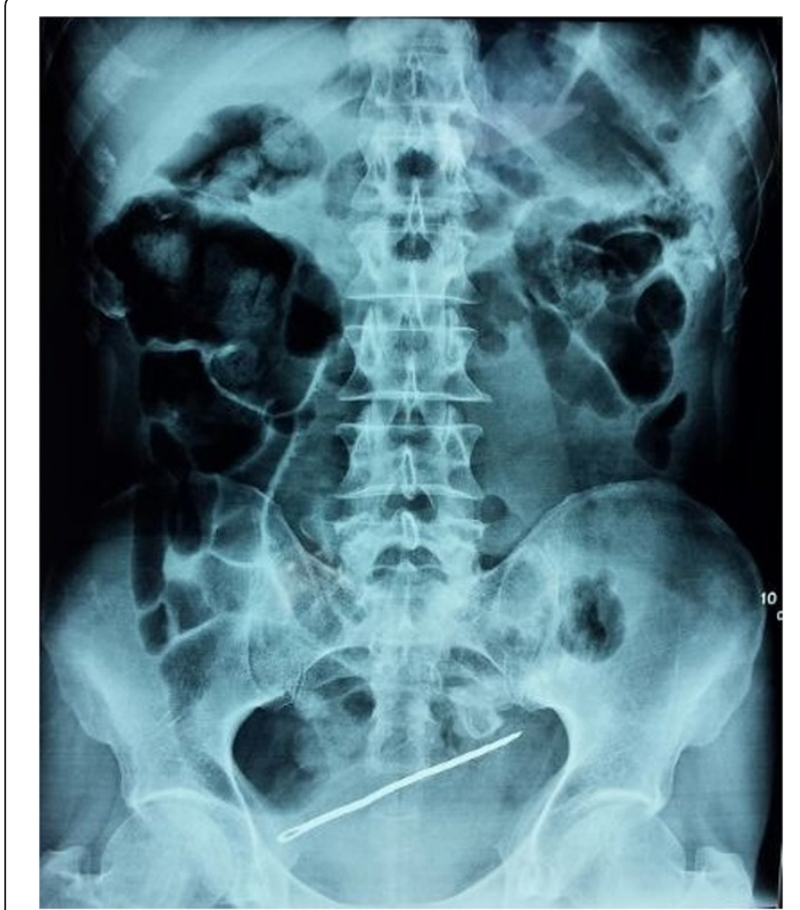

Figure $1 \mathrm{X}$-ray of the patient revealing a sewing needle projecting into the bladder area.

$1000 \mathrm{~mL}$ of widely dispersed fluid was observed in the abdominal cavity. During the exploration of the bladder, two centimetric intrabladder breaches and a breach on the left pelvic ureter were found without other associated lesions. These breaches were repaired by surgical suture, and a ureteral catheter was mounted. The incision was closed primarily in two layers, and a urinary catheter was placed. No problems were encountered during the patient's peri-operative clinical course. The patient received psychiatric care, and his post-operative follow-up was unremarkable.

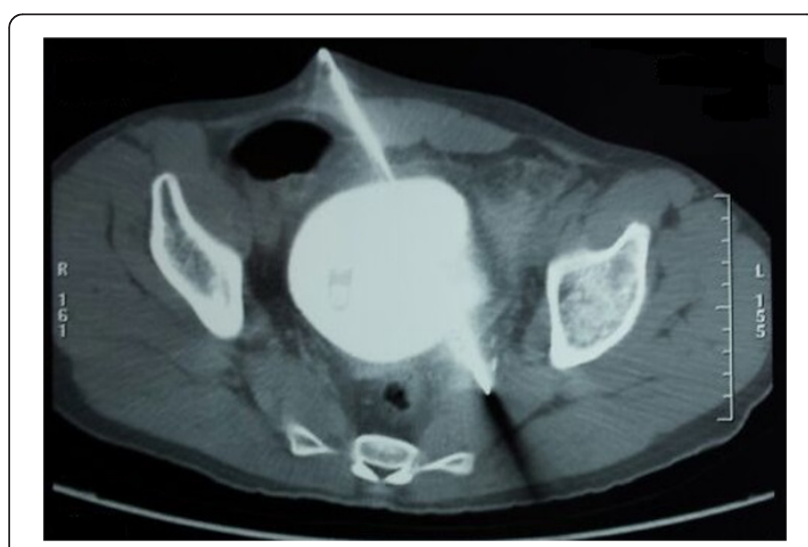

Figure 2 Excretory phase computed tomographic scan showing lesions of the bladder and the left ureter.

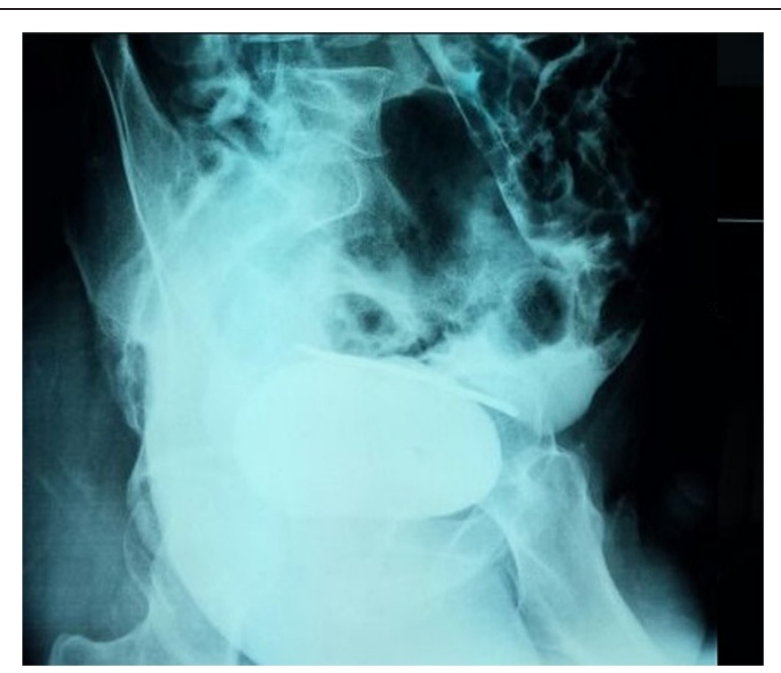

Figure 3 Cystogram showing the sewing needle and contrast extravasation dye.

\section{Discussion}

Foreign bodies in the bladder can occur either by selfintroduction or by migration from adjacent organs [1]. Introduction of foreign bodies can be voluntary and related to a psychiatric disorder or can occur by accidental penetration of objects or iatrogenic trauma due to firearms [2]. This presentation can occur in various situations and can sometimes be life-threatening [3]. It often raises questions about the psychological profile of the patient. Psychiatric disorders have been reported in patients admitted for selfintroduction of foreign bodies into the bladder as an act of sexual satisfaction [4]. However, to the best of our knowledge, no case involving a patient with suicidal intent has been reported in the English-language literature to date. Bladder rupture may be intraperitoneal, extraperitoneal or mixed intra- and extraperitoneal [5].

The clinical presentation of these injuries may vary from simple urinary symptoms suggestive of cystitis to signs of acute abdomen [3]. Signs of bladder injuries may be overlooked, especially in the context of polytraumatized patients, but the presence of the triad of macroscopic hematuria, suprapubic pain and voiding dysfunction suggest the diagnosis and indicate exploration of the bladder [5].

$\mathrm{X}$-rays show a radio-opaque foreign body [2], but they may be unremarkable when the foreign body is radiotransparent. In this situation, an ultrasonogram can objectify bright echogenic foci with distal acoustic shadowing [2].

CT scans of the bladder can be taken in two ways, either by intravenous contrast injection or retrograde filling by contrast dye. The intravenous route is very imprecise in showing bladder rupture because bladder distension is insufficient. A cystogram is preferable in this situation [5] because it has a sensitivity of $95 \%$ and a specificity of $100 \%$ [6]. 
The intra- or extra-peritoneal nature of the injury, which is easily visualized on the cystogram, determines the therapeutic approach to be used. A pelvic CT scan provides valuable information on the status of other pelvic organs as well as the pelvis itself [5]. Cystoscopy may also help in making the diagnosis in the context of radiotransparent foreign bodies by showing their nature and size, and it may also aid in identifying complications. It can be performed for therapeutic objectives for extraction of these bodies when no associated lesions are found, and it may be used in cases of extra-peritoneal bladder breach [7].

The therapeutic approach depends on the patient's condition, the assessment of the lesions, and the size, shape and nature of the intravesical foreign body [8]. The extraction of a foreign body in the bladder can be performed through surgical exploration. A suprapubic cystostomy may be performed for large foreign bodies, when one of the extremities of the bodies is engaged in the bladder wall and when attempts at endoscopic extraction fail [9].

Finally, it is necessary to treat any existing urinary tract infection by using appropriate antibiotics as well as tetanus vaccination, and psychiatric care should be requested to prevent a recurrence when the injury is a result of a voluntary act [10].

\section{Conclusions}

The wide variety of ways that foreign bodies are introduced into the lower urinary tract always raise curiosity because such injuries are often related to sexual or erotic acts in a psychiatric context. To the best of our knowledge, no previous case of attempted suicide by self-stabbing with foreign bodies has been reported to date. Radiology and endoscopy facilitate the diagnosis and therapeutic care in these patients.

\section{Consent}

Written informed consent was obtained from the patient's legal guardians for publication of this case report and any accompanying images. A copy of the written consent is available for review by the Editor-in-Chief of this journal.

\section{Abbreviation \\ CT: computed tomography.}

\section{Competing interests}

The authors declare that they have no competing interests.

\section{Authors' contributions}

YK was the principal author and major contributor in writing the manuscript. ST, MA, SM, JEA, MFT and AK analyzed and interpreted the patient data and reviewed the literature. MJE and MHF read and corrected the manuscript. All authors read and approved the final manuscript.

\section{Acknowledgments}

This study was supported by the Department of Urology, Hassan II University Hospital.

\section{Author details}

${ }^{1}$ Department of Urology, Hassan II University Hospital, Fez, Morocco.

2Department of Anatomy, Faculty of Medicine, Mohammed Ben Abdellah

University, Fez, Morocco.

Received: 12 August 2014 Accepted: 22 September 2014

Published: 27 November 2014

\section{References}

1. Pal DK, Bag AK: Intravesical wire as foreign body in urinary bladder. Int Braz J Urol 2005, 31:472-474.

2. Elhams A, Kabbaj M, Karmouni T, Tazi K, Elkhader K, Koutani A, Ibn Attya AA, Hachimi M: [Foreign body in the bladder: report of 4 cases] [Article in French]. Afr J Urol 2007, 13:226-230.

3. Doganay M, Metin E, Doganay M: Acute abdomen due to a foreign body in the urinary bladder in an adolescent. J Emerg Med 2011, 40:391-392.

4. Datta B, Ghosh M, Biswas S: Foreign bodies in urinary bladders. Saudi J Kidney Dis Transp/ 2011, 22:302-305

5. Shoaib RF, Anwar F, Barron D: Foreign body in Urinary bladder-early CT cystogram is investigation of choice. J Pak Med Assoc 2008, 58:277-278.

6. Power N, Ryan S, Hamilton P: Computed tomography cystography in bladder trauma: pictorial essay. Can Assoc Radiol J 2004, 55:304-308.

7. Robinson D: Foreign body in the bladder. J Emerg Med 2005, 29:215.

8. Rafique M: Intravesical foreign bodies: review and current management strategies. Urol J 2008, 5:223-231.

9. Benchekroun A, Iken A, Nouini Y, Lachkar A, Belahnech Z, Marzouk M, Faik M: [Foreign bodies of the bladder: report of a new case] [Article in French]. Ann Urol 2001, 35:220-222.

10. Caspi B, Rabinerson D, Appelman Z, Karplan B: Penetration of the bladder by a perforating intrauterine contraceptive device: a sonographic diagnosis. Ultrasound Obstet Gynecol 1996, 7:458-460.

doi:10.1186/1752-1947-8-391

Cite this article as: Kharbach et al:: Suicide attempt by self-stabbing of the bladder: a case report. Journal of Medical Case Reports 2014 8:391.

\section{Submit your next manuscript to BioMed Central and take full advantage of:}

- Convenient online submission

- Thorough peer review

- No space constraints or color figure charges

- Immediate publication on acceptance

- Inclusion in PubMed, CAS, Scopus and Google Scholar

- Research which is freely available for redistribution 